\title{
PRÁTICAS DE GOVERNO DAS CRIANÇAS E DOS ADOLESCENTES PROPOSTAS PELO UNICEF E PELA UNESCO: INQUIETAÇÕES A PARTIR DAS FERRAMENTAS ANALÍTICAS LEGADAS POR FOUCAULT GOVERNANCE PRACTICES OF CHILDREN AND ADOLESCENTS PROPOSED BY UNICEF AND UNESCO: CONCERNS FROM THE ANALYTICAL TOOLS INHERITED
} FROM FOUCAULT

Flávia Cristina Silveira Lemos Universidade Federal do Pará, Belém, Brasil

\section{RESUMO}

O artigo em pauta é resultante de fala em mesa-redonda proferida no Colóquio Internacional Michel Foucault, a judicialização da vida, realizado, em outubro de 2011, na Universidade Estadual do Rio de Janeiro. O texto ora descrito é parte de análises realizadas há anos em pesquisas documentais, com as ferramentas de Michel Foucault, com relatórios de agências multilaterais ligadas ao sistema Nações Unidas, em especial, UNICEF e UNESCO, no Brasil. Buscamos interpelar estas práticas e descrever como as mesmas são prescritivas de conduta e são estratégias de governo neoliberal, articulando a promoção, defesa e garantia de direitos à economia política, em nome da defesa da vida e da construção da paz e segurança mundial.

Palavras-chave: biopolítica; documentos; história; UNICEF e UNESCO; direitos de crianças e adolescentes.

\begin{abstract}
The article in question is the reslt of round-table talks given at the International Colloquium Michel Foucault judicialization of life, held in October 2011, at the State University of Rio Janeiro. The text described here is part of the analysis performed for years in documentary research, with the tools of Michel Foucault, with reports from multilateral agencies linked to the United Nations system, particularly UNICEF and UNESCO in Brazil. We seek to challenge these practices and describe how they are prescriptive of conduct and are neoliberal strategies of government, combining the promotion, protection and guarantee of rights to political economy on behalf of the defense of life and peace building and global security.
\end{abstract}

Keywords: biopolitics; documents; history; UNICEF and UNESCO; rights of children and adolescents.

Neste artigo, pretende-se apresentar parte de breves resultados de uma pesquisa e as inquietações que essa vem movendo, nos últimos anos, com estudos documentais, em uma perspectiva da arqueologia e da genealogia, nos estudos históricos de Michel Foucault. Nesse percurso, há dez anos temos interrogado mais de perto os efeitos das práticas de organismos multilaterais, no Brasil; nas políticas que são intituladas de proteção, defesa e garantia de direitos de crianças e adolescentes.

O recorte historiográfico desses trabalhos é o período da Nova República, no Brasil; basicamente, após da segunda metade da década de oitenta do século XX até o presente. Esta escolha visa pensar o que nos acontece no presente e como operam as racionalidades reguladoras em um
Estado governamentalizado. Olhar descontinuamente esse período e recortá-lo em várias séries implica traçar cortes heterogêneos e díspares, raros e singulares, marcados pelo princípio da exterioridade e do acontecimento em sua emergência e proveniência.

$\mathrm{Na}$ arqueologia, analisamos a história da verdade e as condições de possibilidade do aparecimento de saberes, em um determinado tempo e espaço, composto por formações discursivas que não são unidades e sim multiplicidades em movimento no campo dos enunciados deslocados como regimes de dizibilidades e visibilidades. Descrever os enunciados em sua dispersão, em suas relações colaterais e temáticas, nas suas modalidades teórico-conceituais, em seus lugares institucionais e nas posições de sujeito 
que ensejam provisoriamente, no modo como forjaram objetos raros, não se confundindo com as análises dos atos performáticos, das frases e das proposições.

Trabalhamos com uma perspectiva histórica que considera as descontinuidades como uma atualização que implica o retorno como diferença, ou seja, devir. As séries em que são enunciados acontecimentos, dispostas em arquivos múltiplos, entram em composição com arquiteturas, subjetividades, poderes, instituições e corpos, em dispositivos concretos.

Já estamos no plano de composição que opera entremeios entre arqueologia e genealogia, materializadas na análise de uma política da verdade em um campo ético e político, de uma ontologia histórica do presente. Analisar o presente é captar o intolerável hoje, para Foucault, é realizar uma atitude crítica problematizadora, abrindo passagens e engendrando campos de possibilidade, agindo nas e entre as brechas e forças do devir.

Nessa perspectiva, os documentos são arquivos constituídos peça por peça, compondo uma multiplicidade de acontecimentos que, em geral, vem sendo silenciada em prol de uma unidade fictícia que é colocada em xeque por um olhar inquietante. $\mathrm{O}$ documento, assim, é efeito de seleções, recortes, práticas culturais, operações historiográficas, jogos e disputas variados. Um arquivo pode ser capturado em um museu ou não, sendo resultado de uma memória manuseada por artífices da história que tentou torná-lo monumento.

Ora, o que analisamos nos documentos são as prescrições que operam e os assujeitamentos que são produzidos em meio aos jogos de saber-poder que atravessam os modos de escrever, fotografar, editar, engendrar, guardar, preservar, organizar, narrar, registrar e canonizar certas maneiras de ser ou estigmatizar outras como infames.

Assim, o documento não seria uma prova ou testemunho tal qual um vestígio em uma linha do tempo da verdade e dos sujeitos revelados e reveladores nestes procedimentos. Estamos trabalhando com o documento como uma montagem de séries analíticas que se entrecruzam e se compõem, formando um dispositivo.

Perguntamos o que é silenciado em um documento, o que é desqualificado, que embates são travados para dar visibilidades diferenciadas às memórias que estão em jogo. Problematizar prescrições e regulações perpassadas por racionalidades específicas implica em desnaturalizar lugares institucionais, posições de sujeito, continuidades e linearidades, lógicas simplistas e tutelares. Ora, uma história do presente faz do documento um uso político, manejando-o como um artefato cultural para produzir passagens, brechas, espaços para uma atitude crítica frente aos nossos fazeres e aos efeitos dos mesmos.

Dessa maneira, podemos pensar a raridade das práticas, acontecimentalizar e, portanto, fazer algo ranger e interferir no que está posto como legitimado e autorizado, visando tecer tramas e intrigas processuais que possam ser usadas para problematizar nossa atualidade. Após essas considerações iniciais, passamos a apontar algumas análises que estamos fazendo no grupo de pesquisa Transversalizando, ao realizarmos estudos de documentos de organismos internacionais, em especial de agências que compõem o sistema Nações Unidas, nos apropriando do legado de Foucault.

O jogo de interesses políticos, sociais e econômicos que se estabeleceu entre os corpos, materializado nas práticas de governar em nome da paz e de um projeto civilizatório, emerge com o nascimento do Estado nação, tendo no Tratado de Vestefália, em 1648, um dos acontecimentos que visava a moderar uma lógica concorrencial pressuposta pelo liberalismo, após a Guerra dos Trinta Anos (Foucault, 2008a).

A partir desse momento, aparece a noção de que o Estado é um sujeito internacional e tem interesses a serem mediados sem que a soberania de cada país seja colocada em xeque a ponto de romper com esta ordem social. Os filósofos contratualistas, recepcionados pelos economistas e cientistas políticos, irão deslocar o debate sobre direitos, considerando os princípios tanto da Revolução Francesa quanto da Americana para a preocupação com a segurança, ou melhor, realizam uma composição entre ambos.

Nesse momento, a cidadania era postulada como restrita e vinculada à Nação, estando delimitada por ela e não por organizações de direito internacional de maneira mais direta. Para Belli (2009), os aspectos que fizeram desmontar esta ordem da soberania nacionalista foram: o Holocausto, a experiência stalinista da União Soviética, o racismo no sul dos Estados Unidos, o fascismo na Itália e o imperialismo inglês, nas primeiras décadas do século XX, logo após a primeira guerra mundial.

As experiências históricas do multilateralismo remontam ao século XIX, quando as principais potências européias, mediante uma fina engenharia diplomática denominada Concerto Europeu, conseguiram assegurar um século de paz (1815-1914). A eclosão da Primeira Guerra Mundial inaugurou o século $\mathrm{XX}$ e, com ele, uma corrida ao isolacionismo e ao protecionismo sem precedentes na 
história moderna. Com o fim da guerra, em 1919, os países voltaram a apostar na força do multilateralismo, criando a Lida das Nações - embrião do Sistema ONU. (UNESCO, 2002, p. 231).

É nesse momento que surge a Liga das Nações, com o objetivo de evitar outras guerras e promover a paz no mundo por meio da gestão das relações internacionais, começando a criar brechas nos contornos fechados da soberania dos Estados. Com a Declaração Universal dos Direitos Humanos, depois da II Guerra Mundial, aqueles que são denominados de indivíduos passam a ser nomeados como sujeitos de direitos, no plano internacional (Belli, 2009).

Contudo, Michel Foucault (2008a) afirma que, desde a segundametade do séculoXVII, dois dispositivos já estavam em funcionamento concomitantemente nas práticas dos Estados liberais: a polícia como controle do cotidiano dos corpos, urbanização das cidades e medicalização do Estado e os aparatos diplomático-militares, operando na mediação da concorrência internacional, instrumentos de guerra (constituição das forças militares profissionais a serviço dos Estados) e de busca de um equilíbrio internacional em nome da construção da paz, provisoriamente pelo menos (diplomacia) e negociada permanentemente pelos Estados pela via da produção de uma comunidade internacional.

Foucault (2008b) assinala, no curso Nascimento da Biopolitica, que Kant já realizava uma discussão sobre a paz perpétua, negociada entre os Estados republicanos supostamente livres, porém, interligados por meio do contrato social, que seria pautado em: pactos, alianças, convenções, declarações e tratados que impedissem a guerra. E Foucault (2008a) ainda ressalta, em Segurança, território e população, que paralelamente aos dispositivos policiais e diplomático-militares estava sendo formulado um processo de objetivação que fez emergir não apenas as noções de sociedade, de defesa da sociedade, mas também a de sociedade civil mundial, entendida como composição de indivíduos livres que estabeleceriam um pacto pela paze pelo processo civilizacional-desenvolvimentista, ancorado na economia, na ciência política e na administração do Estado moderno (Rodrigues \& Romão, 2006, p. 12).

Assim, evitava-se a violência e a guerra, em consensos engendrados por meio de alianças fixadas em contratos jurídicos e políticos. Os Estados passam a se defender mutuamente em caso de guerras por meio dos acordos de segurança mundial que visam a modular as tensões permanentes que não se apagam com a proposição de uma declaração ou convenção de direitos (Rodrigues \&
Romão, 2006). Mas os princípios das mesmas operam na negociação dessas e, caso sejam rompidos, podem justificar a entrada em cena dos aparatos militares, tanto em contextos internos ao Estado quanto nas relações internacionais.

Assim, este direito internacional não exclui a busca dos Estados pela chamada segurança interna, mas as relaciona sistemicamente no campo das relações internacionais, em jogos de saber-poder vinculados aos dispositivos policiais que normalizam em articulação com a lei. Desse modo, são criados os aparatos diplomático-militares que possibilitam acionarmos acordos que tentem atenuar os dissensos e tensões configurados com a concorrência liberal. No bojo desses acordos, o Estado regula e é regulado, com a emergência do Direito Público e com as mutações da economia política. Assim, configuram-se os mecanismos de segurança, baseados em tecnologias de poder que entrecruzam suplícios, disciplinas e biopolíticas (Foucault, 2008a).

É no bojo desses acontecimentos que a Organização das Nações Unidas foi criada, após a II Guerra Mundial, atualizando a anterior Liga das Nações. A ONU se desdobra em um conjunto de agências, assembleias, conselhos e fundos, tais como a UNESCO e o UNICEF, entre outros.

Construída para ser uma coligação de Estados visando a paz e a segurança internacionais, como atesta o preâmbulo do seu documento de criação, a ONU enfrenta questões derivadas exatamente do espaço de forças em que se constitui: uma organização constrangida, moldada e impulsionada pelos Estados que a conformam e pelas forças não-estatais que têm, gradativamente, conseguido lugar como fontes de pressão e observação. (Rodrigues \& Romão, 2006, p. 14)

A história do UNICEF - Fundo das Nações Unidas para a Infância começou em 11 de dezembro de 1946, dia de sua criação por decisão unânime da primeira Assembléia das Nações Unidas, para dar apoio às crianças européias, vítimas da Segunda Grande Guerra. Em 1950, a atuação do UNICEF foi ampliada para crianças do mundo inteiro. Nesse mesmo ano, foi criado, em João Pessoa, capital da Paraíba, o primeiro escritório do UNICEF, no Brasil. (UNICEF, 2002, p. 01).

Para estes organismos é mais importante manter e construir a segurança mundial como um modo de governar a população e não se restringir apenas ao território e ao conceito de povo na esfera da soberania jurídica. Gerir segmentos da população por meio dos saberes da medicina social, entrelaçada à economia política, em contextos de Estados democráticos de direito passou a ser a tônica de organismos multilaterais, ou pelo menos sua retórica formal. 
Para garantir os direitos de crianças e adolescentes e fortalecer suas competências, o UNICEF, com outros parceiros, prioriza a família: organiza campanhas de sensibilização nos meios de comunicação, produz materiais educativos, apoia projetos de prevenção da violência contra meninas e meninos dentro do meio ambiente familiar, estimula programas de capacitação das famílias e a criação de mecanismos que garantam sua participação em todos os processos de decisão relativos a seus direitos e de suas crianças. (UNICEF, 2002, p. 3)

Essas redes, apoiadas por governos, organizações da sociedade civil e principalmente das comunidades, devem ser capazes de engajar as famílias em processos de aprendizado e aquisição de habilidades para cuidar das crianças em casa, de forma a melhorar o desenvolvimento infantil nas áreas física, emocional, social e cognitiva. (UNICEF, 2001, p. 11)

Com as últimas descobertas científicas sobre o desenvolvimento da criança na primeira infância, podese dizer que os ensinamentos sobre a igualdade de gênero, o respeito pelos direitos de todos os indivíduos, o reconhecimento das diversidades culturais e as noções de tolerância e paz devem começar nos primeiros anos de vida da criança. (UNICEF, 2001, p. 11)

Um dos segmentos mais privilegiados de governo das condutas passou a ser a família a ser medicalizada para que fosse medicalizante dos filhos (Foucault, 1979) e, dessa forma, a infância considerada em perigo e perigosa ganha visibilidade política e econômica, como o futuro da Nação e enquanto membro da comunidade internacional.

Os custos de dar ao adulto uma segunda chance na vida são muitos maiores do que os custos de se prover cuidados no tempo adequado à criança, principalmente em seus primeiros anos de vida. $\mathrm{O}$ investimento na criança oferece de melhor aproveitamento escolar, maior produtividade e comportamentos positivos ao longo da vida. Serviços sociais básicos de saúde e educação, por exemplo, são investimentos preventivos muito mais efetivos e humanos. (UNICEF, 2001, p. 17)

Provavelmente o parâmetro mais importante para avaliar se uma economia é bem-sucedida não tem a ver com as medidas econômicas convencionais, mas é o que é feito pelas crianças - na medida em que a sociedade lhes garante os direitos indiscutíveis indicados pela ética mais fundamental e pelas constituições democráticas. Muitos países da América Latina estão longe de serem aprovados neste quesito. (UNESCO, 2008, p. 102)

À ação pública, mediante políticas agressivas em favor da infância desvalida, deve-se somar uma grande mobilização da sociedade civil, com a colaboração de empresas privadas socialmente responsáveis, de voluntários, de organizações de todo tipo, que podem contribuir para uma execução eficiente das políticas públicas e acrescentar recursos e iniciativas criativas. São notáveis os êxitos alcançados pelo UNICEF e por instituições como Caritas, Fé e Alegria, Casa Aliança entre outras. (UNESCO, 2008, p. 103)

A Pastoral da Criança é um projeto-referência para todo o atendimento em saúde e educação a famílias e crianças. Com o trabalho de mais de 127 mil líderes comunitários voluntários, movidos pela solidariedade e pela fé, a Pastoral transforma as comunidades onde atua. (UNICEF, 2001, p. 31)

Ligada à Conferência Nacional dos Bispos do Brasil (CNBB), a Pastoral da Criança promove ações de melhoria da saúde das crianças e suas mães, orienta os homens sobre o papel do pai no desenvolvimento da criança, distribui a multimistura (uma opção barata e eficaz de combate à desnutrição), alfabetiza homens e mulheres, mantém brinquedotecas e apóia ações de geração de renda para famílias pobres. Um dos resultados de maior impacto da atuação da Pastoral em todo o país é a redução drástica nos índices de mortalidade infantil. (UNICEF, 2001, p. 31)

O UNICEF opera o governo de condutas, tais como: gestão da educação, da família, da criança pequena, do adolescente, da proteção e da punição, da saúde, da assistência social, do controle e prevenção da violência, da equidade no atendimento, no monitoramento das políticas, na rede de organizações governamentais e não governamentais, agindo como articulador político. Há muitos programas e projetos no Brasil, com intervenção direta ou indireta deste fundo ligado às Nações Unidas. Um dos principais focos desse organismo tem sido a família, em especial, a relação mãe e filhos, que passou a ser compreendida como prioritária na política de proteção de crianças e adolescentes. O UNICEF chega a falar de capacitação das famílias para que essas adquiram competências de educação.

A UNESCO focaliza a educação, a ciência e a cultura e afirma que a guerra nasce na mente dos homens. Portanto, é neste prisma que a mesma poderá ser evitada. Assim, essa agência realiza programas, projetos, congressos, convenções, financiamentos, publica livros e relatórios para prevenir a guerra, promover a paz e a segurança mundial. Um dos programas mundiais por ela veiculados é um que atua nas escolas, com esportes e arte, nos finais de semana.

Quero, primeiramente, dizer que um evento científico internacional, organizado sobre um tema de grande atualidade como Esporte e Inclusão Social, situa-se entre as prioridades que a UNESCO elegeu como sendo indispensáveis a sua política mundial em prol do desenvolvimento humano sustentável, com qualidade. ... A UNESCO, em sua experiência mundial de lutas para o desenvolvimento de uma cultura de paz, sempre viu e percebeu a enorme potencialidade dos esportes como estratégia ímpar, não somente para a auto-realização das pessoas, como também 
para a aproximação das pessoas e das culturas, condição indispensável para o desenvolvimento e fortalecimento da compreensão internacional. ... Os princípios da cultura de paz, por intermédio do esporte, possam promover o diálogo comunitário e contribuir para a prevenção dos conflitos e da violência. (UNESCO, 2002, pp. 33-35)

Outros programas também são propostos e digamos que são induzidos, como: a salvaguarda do chamado patrimônio histórico-cultural, a gestão da produção do conhecimento, as recomendações de como utilizar cada nível de oferta da educação escolarizada e de como gerir a pesquisa dirigida ao desenvolvimento e inovação social e econômica.

É importante destacar que analisamos como estas agências acionam práticas vizinhas, tais como Veyne (1998) afirmava, ao pensar como Foucault analisava as relações de saber, de poder e de subjetivação enquanto práticas concretas, sem um sujeito ou instituição pela qual se abateria o poder. Desse modo, os órgãos da ONU tentam intervir e fazem pressões, mas também são pressionados e constituem alianças, sofrem resistência e, mesmo em nome da prevenção da guerra, chegaram a autorizar as guerras.

Não podemos problematizar essas práticas sem pensar a dispersão de forças, sua multiplicidade e de que modo a raridade dos acontecimentos se materializam em meio à objetivação da paz e da segurança internacionais. Sem um Estado que judicializa a vida, a ONU não pode agir, entretanto, esta contratualização intensiva precisa ter a flexibilidade da liberdade, dos cálculos políticos e econômicos para que a mesma ocorra, bem como deve render lucros e propiciar circulação de bens, de corpos, de alimentos, de produtos, de conhecimentos com seguridade empresarial e educação permanente.

Nessa lógica, tudo se tornou investimento, inclusive a garantia de direitos e a defesa da criança, na ordem internacional neoliberal, sob a rubrica da segurança mundial e do fomento à paz, pois uma das racionalidades atuais é que o impedimento da concorrência dos mercados é considerado pelos liberais como um fator que pode desembocar em guerras. Assim, esses organismos calculam o impacto econômico, e o que denominam desenvolvimento de cada prática de proteção de direitos, sujeitos de direitos e sujeito econômico são colocados em articulação política (Foucault, 2008b).

Assim, a gestão da população e a regulamentação por meio da lei se mesclam, nas tentativas de assegurar liberdade com segurança de modo concomitante, população e povo em jogo, sujeito de investimento econômico e sujeito de direitos entrelaçados, norma e lei. A liberdade é muito relevante para a governamentalidade, pois é por meio dela que a ONU propõe a gestão das populações pela mobilização de saberes/poderes operacionalizados pela regulação com normas em meio ao aparato jurídico de regulamentação das liberdades, em um sistema de direitos e deveres, de acordo com Foucault (2008b).

As práticas vizinhas desses organismos operam na comunicação em redes com inúmeras organizações governamentais e não-governamentais locais, regionais e internacionais, por exemplo, por meio de assessores contratados por projeto ou do próprio quadro da agência, sendo que esses especialistas podem ser também pesquisadores das universidades, integrantes de fundações, funcionários de bancos, membros de OSCIPs e ONGs. Piaget, Wallon, Morin, Alan Touraine foram assessores desses organismos, e economistas como Amartya Sen e Ignacy Sachs são citados como verdadeiros gurus dessas agências. No caso de Sen, foi presidente do banco mundial, considerado juntamente com Sachs indutores da racionalidade do desenvolvimento sustentável como vetor transversal de todas as práticas da UNESCO e da UNICEF.

Uma das mais surpreendentes mudanças no multilateralismo contemporâneo, é o surgimento da sociedade civil como partícipe da diplomacia. Este processo teve início também no Rio de Janeiro, quando a Conferência sobre Meio Ambiente, em 1992. A série de conferências mundiais patrocinadas pela ONU vem fortalecendo esta tendência. (UNESCO, 2002, p. 232)

Essas agências atuam conjuntamente com uma rede pulverizada de estabelecimentos, organizações, efetuam conluios com os Estados governamentalizados, tendo interferência intensiva nas políticas públicas brasileiras. Bancos como o Itaú financiam a publicação dos relatórios; a Rede Globo realiza a Campanha Criança Esperança com a UNESCO e pede doações, levando artistas para mobilizar o país à caridade e à filantropia, atualizadas no complexo tutelar. Anteriormente, a Campanha Criança Esperança era feita com a UNICEF, depois passou a ser realizada com a UNESCO.

Criança Esperança é uma campanha anual de mobilização de recursos e de conscientização da população, realizada desde 1986 por meio de uma parceria do UNICEF com a Rede Globo. Os fundos são integralmente repassados para instituições que atendem diretamente crianças e adolescentes unicamente no Brasil. Além de arrecadar fundos, o Criança Esperança incentiva a população e o Governo a encontrar soluções para diminuir a mortalidade infantil, melhorar a qualidade da educação, promover o aleitamento materno, combater a exploração sexual e erradicar o trabalho infantil. Outro objetivo da parceria entre o UNICEF e a Rede lobo é incentivar empresas privadas a investir na melhoria das condições de vida das crianças e adolescentes brasileiros. (UNICEF, 2002, p. 29) 
Recentemente, vi em uma Livraria Saraiva ser vendido um mapa do Brasil com a imagem de uma criança como fundo da ordem e do progresso e da imagem da floresta. Emblemático esse documento da visão desenvolvimentista e econômica da criança como futuro e como investimento, bem como da constituição da ordem, em um quadro de geopolítica territorial em intercâmbio com a biopolítica.

Desde 1948, a UNESCO vem acompanhando a evolução das agendas internacionais com uma missão específica: oferecer insumos concretos para a pacificação das relações internacionais. ... Não é de hoje que os países do mundo lançam mão do princípio do multilateralismo como forma de administrar as relações internacionais. (UNESCO, 2002, pp. 221-231)

As práticas dessas agências sempre invocam os saberes designados como evidência científica para validar suas receitas neoliberais também nomeadas pelas mesmas como práticas exitosas a serem reproduzidas em diferentes locais, regiões e países. Nesse sentido, vale mencionar como nossa escrita da história do presente, problematizando as intervenções de organismos internacionais, no Brasil tem relação com a apropriação dos dizeres de Michel Foucault (1999) quando este ressalta que o objeto da história que fazia era a colonização imperialista que ainda é um tema extremamente atual com as práticas de demarcação entre hemisfério sul e norte, classificações de países desenvolvidos, em desenvolvimento e não desenvolvidos, subdesenvolvidos, primeiro mundo e terceiro mundo, centro e periferia etc.

Também vale destacar que há citações permanentes de pesquisas realizadas pelo Banco Mundial, nos relatórios das agências em pauta e intensa sensibilização de empresas ao convite de mobilização social e de realização de um projeto de participação denominado de responsabilidade social com articulações entre organizações variadas, inclusive com as comunidades e com as pastorais. A UNESCO (2003) chega a destacar que todo este aparato pode ser entendido como sinergia social, capital social organizado em formato de terceiro setor.

O Programa das Nações Unidas para o Desenvolvimento destaca a participação como uma estratégia central de mudança nos seus difundidos Relatórios sobre o Desenvolvimento Humano Mundial. ... A participação comunitária pode ser uma ferramenta fundamental diante dos graves problemas sociais que a América Latina enfrenta. (UNESCO, 2003, pp. 177-178)

O capital social está sendo redescoberto hoje como uma chave estratégica dos avanços registrados em países bem sucedidos. ... Por capital social se entende um conjunto de aspectos tais como, dentre outros: a capacidade de uma sociedade para produzir amplos acordos sociais no seu interior, para gerar redes articuladoras dos esforços de seus diversos setores; as forças existentes numa sociedade para dar impulso ao trabalho voluntário em iniciativas de utilidade geral; sua cultura, e a presença de valores éticos voltados para a solidariedade, a construção positiva, a cooperação e a equiidade. ... Os países que protegem, fortalecem e mobilizam seu capital social estão potencializando uma das alavancas decisivas de desenvolvimento (UNESCO, 2003, p. 161)

A participação da comunidade está sendo hoje revista como poderoso instrumento para o desenvolvimento.... O Programa das Nações Unidas para o Desenvolvimento destaca a participação como uma estratégia central de mudança nos seus Relatórios sobre o Desenvolvimento Humano Mundial. (UNESCO, 2003, p. 177)

Noções como: capital humano e social, redução da pobreza, desenvolvimento econômico e social, investimento e impacto no PIB, inovação tecnológica, competência e habilidades, comunidade internacional, prevenção e gestão de risco/perigo, educação para a paz, famílias vulneráveis, equidade, iniquidades que tiram oportunidades de se tornar empresário de si são invocadas com frequência por essas instâncias em suas práticas de pressão e articulação política nos países em que atuam, também chamados de países pobres, periféricos ou em desenvolvimento pelas agências em pauta. A biopolítica em um campo de gestão racista entra em cena na ligação entre proteção e segurança pela insígnia de direitos a defender e garantir.

Para Sen, a preocupação pelo ser humano concreto deve alimentar as análises econômicas de forma permanente. ... A América Latina parece insistir em produzir debates de qualidade sobre como ativar valores culturais que estimulem a participação cidadã, o voluntariado, a responsabilidade social do empresariado, o fortalecimento geral da solidariedade. (UNESCO, 2003, pp. 186-191)

Os países que protegem, fortalecem e mobilizam seu capital social estão potencializando uma das alavancas decisivas do desenvolvimento. ... O tema do capital social tem despertado grande interesse internacional, e existe uma verdadeira explosão de pesquisas e trabalhos sobre a matéria. Dentre outras organizações, o Banco Mundial está estudando como consegue avaliar seus projetos, em termos de resultados do desenvolvimento do capital social. O BID organizou o Seminário Internacional (Paris, 1999) sobre o papel do capital social e da cultura no desenvolvimento. (UNESCO, 2003, pp. 161-164)

Torna-se urgente superar os mitos, passar para a ação, unir esforços, e enfrentar a pobreza e a iniquidade com um investimento social sustentado, administrado com critérios avançados de gerenciamento social, e projetado para 
potencializar as pessoas, o principal recurso e o fim último de toda sociedade democrática. (UNESCO, 2003, p. 152)

É evidente que o custo econômico da exclusão e da iniqüidade torna os países com forte discriminação de amplos setores da sociedade menos competitivos no cenário global. ... Não investir no desenvolvimento do potencial dos talentos de todas as pessoas, nas suas capacidades e habilidades coloca os países em risco nessa atual fase de interdependência global. (UNICEF, 2003, p. 33)

Segundo análise do Banco Mundial há quatro formas básicas de capital: o natural, formado pela dotação de recursos naturais com que conta o país; o construído, gerado pelos seres humanos, sob diversas formas: infra-estrutura, bens de capital, capital financeiro, comercial etc., o capital humano, determinado pelo nível de alimentação, saúde e educação da população; e o capital social, descoberta recente das ciências do desenvolvimento. Alguns estudos indicam atribuem às duas últimas formas de capital importância predominante no desenvolvimento econômico das nações no fim do século $\mathrm{XX}$ e indicam que elas são fatores decisivos para o progresso tecnológico, a competitividade, o crescimento sustentado, o bom governo e a estabilidade democrática. (UNESCO, 2008, pp. 50-51)

Mas podemos nos perguntar se os Estados apenas obedecem a estes parâmetros, mesmo quando os ratificam e dizem que irão segui-los, ou ainda podemos nos perguntar se os projetos e programas financiados e assessorados por estas agências são executados tal como foi estabelecido nos tratados e contratos realizados. Ou podemos também pensar e indagar se a população-alvo destas políticas apenas aceita o lugar de vítima e de passividade receptiva de políticas compensatórias prescrito por estes projetos e programas.

Tais perguntas nos fazem analisar as resistências e as intrigas e tramas que ocorrem no jogo de Estados compósitos, grupos que se agenciam ou não, corpos que se encontram, e é nos entremeios dos encontros que se dá o que Foucault nomeou de agonística. Esta filosofia das relações dinâmicas, móveis, diagonais e transversais entre micropolítica e macropolítica possibilita fazer operar as dissidências, as revoltas, os deslocamentos, o acaso e a singularização dos modos de existência mesmo quando a modulação do capital se torna mais flexível e de rápida rotação.

Para Sen, a preocupação pelo ser humano concreto deve alimentar as análises econômicas de forma permanente. ... Na concepção de Sen, a obtenção de um progresso econômico tem a ver com critérios que superam as visões convencionais. $\mathrm{O}$ desenvolvimento social é peça-chave para o crescimento econômico. As condições de nutrição, saúde e educação da população de um país terão forte influência sobre o desenvolvimento. Como hoje é admitido, o capital humano é fundamental. (UNESCO, 2003, pp. 186-7)

É indispensável, então, ter uma visão multidimensional para se encontrar uma solução efetiva e sustentável para a pobreza. Será preciso um aumento substancial das capacidades de todas as pessoas, principalmente das pessoas atingidas por grande iniqüidade, como os pobres, as mulheres, os afrodescendentes e os indígenas, as pessoas com deficiências, entre outras, para que vivam uma vida mais saudável, longa e produtiva; para que participem ativamente do processo de desenvolvimento; e aproveitem com satisfação de todos os seus direitos humanos. (UNICEF, 2003, p. 48)

Finalizando, vale destacar que a história dessas práticas dá visibilidade para a abertura de possibilidades outras que não se limitem às tentativas de captura dos mecanismos de segurança e seguridade, na atualidade, que permitam a produção de resistências às empreitadas liberais e neoliberais de conduzir pastoralmente nossas existências pelo cálculo econômico e político das relações entre liberdade e segurança, em nome de pressupostos de paz e de civilidade.

Portanto, é relevante notar como, na atualidade, certas maneiras de existir são constituídas e como as mesmas ensejam modos específicos de controle social e político em nome da vida. Michel Foucault denominou esses mecanismos de biopolítica ou gestão da vida em prol da seguridade e da proteção. O sujeito econômico é entrecruzado ao sujeito jurídico de direitos com as práticas de agências multilaterais, que se tornaram dispositivos diplomáticos na cena internacional da história do presente e que se intitulam vetores da consciência mundial, desde a segunda guerra mundial. Estas práticas são forças e contraforças de jogos de poder-saber-subjetivação, que podem promover direitos, mas também podem realizar chantagens e estratégias de mediação de interesses outros em nome da retórica da segurança, da paz e da proteção.

\section{Referências}

Belli, B. (2009). A politização dos direitos humanos: o Conselho de Segurança de Direitos Humanos das Nações Unidas e as resoluções sobre países. São Paulo: Perspectiva.

Foucault, M. (1979). Microfisica do poder. Rio de Janeiro: Graal.

Foucault, M. (1999). Em defesa da sociedade. São Paulo: Martins Fontes.

Foucault, M. (2008a). Segurança, território e população. São Paulo: Martins Fontes.

Foucault, M. (2008b). Nascimento da Biopolítica. São Paulo: Martins Fontes.

Rodrigues, T. \& Romão, W. M. (2006). A urgência em problematizar as Nações Unidas. In T. Rodrigues \& W. M. 
Romão (Orgs.), ONU no século XXI: perspectivas (pp. 0915). São Paulo: Desatino.

United Nations Children's Fund - UNICEF. (2001). Relatório: Situação da infância brasileira. Brasília: UNICEF.

United Nations Children's Fund - UNICEF. (2002). Relatório: Fazer valer os direitos das crianças e dos adolescentes. Brasília: UNICEF.

United Nations Children's Fund - UNICEF. (2003). Relatório da situação da infância e adolescência brasileiras: diversidade e equidade. Pela garantia dos direitos de cada criança e adolescente. Brasília: UNICEF.

United Nations Educational, Scientific and Cultural Organization - UNESCO. (2002). Construção e identidade: as ideias da UNESCO no Brasil. Brasília: UNESCO.

United Nations Educational, Scientific and Cultural Organization UNESCO. (2003). Por uma economia com face mais humana. Brasília: UNESCO.

United Nations Educational, Scientific and Cultural Organization UNESCO. (2008). Mais ética, mais desenvolvimento. Brasília: UNESCO.

Veyne, P. (1998). Como se escreve a história. Brasília: UNB.
Recebido em: 02/01/2012

Aceite em: 09/03/2012

Flávia Cristina Silveira Lemos é graduada em Psicologia pela Universidade Estadual Paulista Júlio de Mesquita Filho (1999), Mestre em Psicologia e Sociedade (2003) e Doutora em História e Sociedade pela Universidade Estadual Paulista Júlio de Mesquita Filho (2007). Foi bolsista CAPES no mestrado e FAPESP no doutorado. Professora adjunta de psicologia social na UFPA, campus Belém/PA. Endereço: Av. Almirante Barroso, 2010, bl. A, 1004, Marco, Belém/PA, Brasil. CEP 66093-907. Email: flavazevedo@hotmail.com

\section{Como citar:}

Lemos, F. C. S. (2012). Práticas de governo das crianças e dos adolescentes propostas pelo UNICEF e pela UNESCO: inquietações a partir das ferramentas analíticas legadas por Foucault. Psicologia \& Sociedade, 24(n. spe.), 52-59. 